\title{
The confused patient in the acute hospital: legal and ethical challenges for clinicians in Scotland
}

\author{
D Lyons \\ Chief Executive, Mental Welfare Commission for Scotland, Edinburgh, Scotland
}

This review is based in part on a presentation given by $\mathrm{Dr}$ Lyons at the RCPE Symposium on The Confused Patient in the Acute Hospital on 7 September 2012.

\begin{abstract}
Treating the confused patient in a general hospital presents legal and ethical challenges for clinicians. The Mental Welfare Commission for Scotland, as a safeguarding organisation, has developed a body of knowledge and guidance on these matters. This paper summarises some of the advice and guidance we have given and directs clinicians to other relevant documents. Visits to patients receiving treatment in general hospitals have shown that clinicians do not always assess capacity or adhere to the law on consent to treatment. Patients may be unlawfully deprived of liberty because of inappropriate or unlawful restraint. As a result, patients' human rights may be infringed and clinicians may risk legal challenges to their actions. By following best practice in assessing capacity, providing treatment and using restraint ethically, clinicians can avoid these problems. The Mental Welfare Commission welcomes requests for advice in difficult cases.
\end{abstract}

Correspondence to $D$ Lyons Mental Welfare Commission for Scotland Thistle House 9 I Haymarket Terrace Edinburgh EHI2 5HE, UK

tel. $+44(0) / 3 I 3 / 38777$ e-mail Donald.lyons@mwcscot.org.uk

KEYWORDS Incapacity, mental health, legal, ethical, capacity, consent

DECLARATION OF INTERESTS No conflicts of interest declared.

\section{INTRODUCTION}

Scotland has been at the forefront of developing legislation to support decision-making for individuals who lack capacity. Recent legislation, notably the Adults with Incapacity (Scotland) Act 2000 and the Mental Health (Care and Treatment) (Scotland) Act 2003, have earned international recognition as progressive acts that offer protection to individuals while allowing for appropriate substitute decision-making. But this is a complex area with many challenges for the clinician.

This paper will outline some of the main dilemmas facing the clinician in the acute hospital when providing care and treatment for an individual who lacks capacity in relation to important health, welfare or financial decisions. It will review the legislative framework and provide examples of situations where clinicians may struggle, as well as some potential solutions.

The Mental Welfare Commission for Scotland has a general safeguarding role for these individuals. We have a number of specific duties including giving advice, promoting best principle-based practice, visiting individuals and conducting investigations.

\section{THE LEGAL FRAMEWORK IN SCOTLAND}

It is only possible to give a broad picture of the laws that apply to treating the confused patient in the general hospital in this paper. There are definitive texts on the legislation ${ }^{1,2}$ and several codes of practice. Briefly, the legislative framework includes:

- The Human Rights Act (1998);

- The Adults with Incapacity (Scotland) Act 2000;

- The Mental Health (Care and Treatment) (Scotland) Act 2003;

- The Adult Support and Protection (Scotland) Act 2007.

The Human Rights Act is important because it cements the articles of the European Convention on Human Rights (ECHR) within Scottish law. This means that the law itself, and the actions of all of us when undertaking public duties, must comply with ECHR. The most important articles are:

Article 2: the right to life. This is not an absolute right, e.g. you don't necessarily have a right to life when you endanger the life of someone else.

Article 3: the right to be free from torture or inhuman or degrading treatment. This is an absolute right. The test of what constitutes an article 3 breach is quite high, but the risk of breaching this article enters clinical practice at times.

Article 5: the right to liberty and security of person. Under this article, 'persons of unsound mind' can be deprived of liberty but only in accordance with a procedure prescribed by law and only if there is a right of appeal to a competent court. Case law also requires periodic judicial review of all long-term deprivations of liberty. 
Article 6: the right to a fair trial. This applies to civil as well as criminal procedures. In defence of civil rights, including deprivation of liberty, the individual must have the right to representation and there must be an adversarial nature to proceedings.

Article 8: the right to private and family life. Any interference in individual privacy must be in pursuit of a legitimate aim, proportionate and lawful.

The Adults with Incapacity Act (the 2000 Act) governs most interventions in general hospitals for adults who lack capacity to consent to being in hospital and/or receiving treatment. It contains:

A list of principles that must be observed: benefit for the individual, least restriction of freedom, taking account of the individual's past and present wishes, consulting relevant others where practicable and (for some persons who have duties under the $2000 \mathrm{Act}$ ) encouraging use of existing skills or developing new skills.

A definition of incapacity; being incapable of acting, or making decisions, or understanding, or communicating them, or retaining the memory of decisions by reason of mental disorder or inability to communicate due to physical disorder. This is explored further below.

A graded list of interventions, going from least to most restrictive. This includes individuals appointing their own welfare or financial attorneys when capable, management of funds in hospitals and care homes, medical treatment, intervention orders and guardianship.

The Mental Health (Care and Treatment) Act (the 2003 Act) specifically covers treatment for mental disorder.Treatment has a broad definition and can include care, nursing and rehabilitation in addition to specific physical and psychological therapies. The most relevant parts of the 2003 Act are:

Principles governing interventions, several of which are similar to the principles of the 2000 Act.

Emergency and short-term detention in hospital for up to 72 hours and 28 days respectively. General hospital doctors may issue emergency detention certificates. The grounds for compulsion are set out in section 36 of the 2003 Act and it is important to document on the certificate why the grounds are met and, if there is no consent from a mental health officer, what steps the doctor took to try to obtain consent. Without these, the detention may be unlawful. Only approved medical practitioners under the Act can issue short-term detention certificates.

Long-term compulsory treatment orders that may authorise detention in hospital or compulsory community treatment. These are granted, on application, by the Mental Health Tribunal for Scotland. This body also hears appeals against detention.
Appeals against unlawful detention. Section 291 is an important section for general hospital practice. Anyone with an interest in the individual's welfare (including the individual him/herself) can ask the Tribunal to rule that the individual is being detained unlawfully. This has been used to challenge de facto detention of confused individuals who are prevented from leaving hospital although not formally detained.

Warrants to enter premises or to remove individuals. These can be used to remove individuals from home to hospital if they have a mental disorder resulting in refusal of treatment for a physical disorder.

The Adult Support and Protection Act (the 2007 Act) offers a range of intervention to protect adults at risk from harm, abuse or neglect. It places the primary duty for this on local authorities but there are duties placed on other organisations, including the National Health Service (NHS), to cooperate.

The 2007 Act is also important in that it amended the Social Work (Scotland) Act 1968. A new section (I3ZA) gives the local authority the authority to provide care, including residential care. Guidance states that this can only be used if the adult does not resist or object and there is no disagreement about the care required. This section cannot be used if there is a welfare guardian, or application for guardianship, with the power to decide residence.

Other international conventions are also important, while not necessarily a formal part of the law in Scotland. The International Convention on the Rights of Persons with Disabilities is particularly important. It asserts the rights to the highest achievable standard of physical and mental health and the right, where possible, to exercise capacity in making decisions.

\section{PROBLEM SCENARIOS}

The rest of this paper consists of analyses of legal and ethical scenarios that confront general hospital staff when providing care and treatment for confused patients. Case examples, where used, are already in the public domain from reports by the Commission or others.

\section{Assessment of capacity}

Visits and inspections by the Commission ${ }^{3}$ and Healthcare Improvement Scotland ${ }^{4}$ have revealed a lack of documented assessment of capacity to consent to treatment. This is important; treatment without consent must be legally justified and authorised.

Some general points first. There is a presumption in law in favour of capacity. This presumption can be rebutted if there is evidence to the contrary. It can be dangerous to assume capacity without a proper examination to 
test it. Also, capacity is decision-specific. The patient may be capable in relation to some decisions but not others.

Case example: in the Commission's report on 'Mrs T', ${ }^{5}$ we criticised social workers for assuming capacity. Mrs T was known to have a degree of dementia. She had been in hospital several months previously where she was judged capable in relation to decisions about medical treatment. At home, there was evidence she was in distress and may have been subject to abuse by a relative. The local authority was unable to make contact with her but assumed, on the basis of previous assessments that she had capacity to make her own decisions and did not pursue intervention using statutory powers. This was a serious error and resulted in her being subject to continued abuse.

Also, every effort must be made to enhance capacity. This may involve providing information in the most accessible format, ensuring the patient has time and support to make decisions and, for some patients, involving speech and language therapists to maximise communication.

A patient may lack capacity because of mental disorder or inability to communicate because of physical disorder. Mental disorder is defined broadly; mental illness, learning disability or personality disorder but with some exclusions. For example, drug or alcohol misuse and 'acting as no prudent person would act' are not in themselves mental disorders and therefore do not constitute incapacity. Inability to communicate is specific, not part of more global brain injury and must be one that cannot be overcome by translation or mechanical means.

Most assessments of capacity relate to the provision of medical treatment. In this regard, the definition of incapacity in the $2000 \mathrm{Act}$ is consistent with the legal test of capacity in relation to medical treatment $(\operatorname{Re} C)^{6}$ and guidance from the UK General Medical Council (GMC). ${ }^{7}$

The 2000Act contains the criteria of making, understanding and communicating decisions. This is consistent with the requirements to understand, believe, weigh and judge information, arrive at a decision and communicate it, as per the GMC guidance. Patients with mental illness, including delirium and dementia, or with learning disability, may lack the ability to process information. False beliefs may result in inability to believe information.

A note of caution is required here. There is a danger in assuming that a decision to, for example, refuse medical treatment, made by a mentally ill patient is made on the basis of incapacity, especially when it appears unwise. In our guidance on consent to treatment, ${ }^{8}$ we discuss the concept of emotional decision making. We all make emotional decisions in everyday life. They can impact on treatment decisions but do not, in themselves, constitute incapacity.
Case example: a man with moderate to severe depression is offered electroconvulsive therapy (ECT) but refused. He understood that he had a depressive disorder and that ECT was a valid treatment. He read information about ECT and understood its risks and benefits. He refused because he did not like the idea of electricity being put through his brain. This was an emotional decision but he was judged capable of making it.

Memory is a more difficult issue. It may not be enough merely to retain information long enough to make a decision, especially if the decision involves ongoing treatment or has far-reaching consequences on welfare or financial management. Likewise, it is impracticable to require the individual to spontaneously recall all decisions. If the individual is able to retain information long enough to make a decision and either makes the same decision consistently given the same information or recognises the decision as his/her will when presented with a record of it, then that probably constitutes capacity on the basis of memory.

Capacity to act is also required under the 2000 Act. This may not be relevant for medical treatment decisions where the individual may not need to take positive action. It is relevant for other welfare and financial issues where the individual may need to take positive action to safeguard welfare and finances.

Case example: the Commission reported on the case of Mr and Mrs D. ${ }^{9}$ They were a couple who had learning disabilities. They gave power of attorney to a relative under duress and in a situation where we did not think they could possibly have understood all the consequences. When there was evidence that the attorney was misusing financial and welfare powers, statutory services made the assumption that $\mathrm{Mr}$ and Mrs $\mathrm{D}$ could revoke the powers. Because they had learning disability and saw the attorney as having authority over them, they lacked the capacity to act. This was not given enough consideration and they continued to suffer ill-treatment.

This case also raised the issue of undue influence. Legal and medical practitioners did not consider sufficiently the influence that the relative exercised over $\mathrm{Mr}$ and Mrs $D$ when they were persuaded to sign a power of attorney. This is a risk when the action is instigated by the proposed attorney, not the individual; a common situation.

Without a proper assessment of capacity, the patient is at risk of unlawful treatment or lack of protection against abuse. The practitioner risks criticism and possibly legal consequences. To avoid this:

- Assess and document capacity on admission and at key critical decision points for treatment, welfare and financial interventions. 
- Use the functional assessment of capacity in the 2000 Act and GMC guidance.

- Make your assessment specific to the decision. Do not assume that the presence of delirium or dementia automatically means that the patient lacks capacity.

- Take particular care when a patient is being asked to sign a legal or financial document. Pay particular attention to the capacity to act without being subjected to undue influence.

\section{Treatment where the patient cannot consent}

In Scotland, there is a legal requirement to certify incapacity where an adult cannot consent to medical treatment. Under the 2000 Act, medical treatment is defined very broadly as 'any healthcare procedure designed to promote or safeguard the physical or mental health of the adult'. This broad definition gives rise to problems in interpreting and operating this part of the legislation.

Examination usually requires assent from the patient, although verbal consent is more specifically given for intimate examinations, e.g. breasts, rectum or genitalia, or for invasive investigations. It was probably not the intention of the legislation to require certification before an adult with incapacity could be examined, but it may be needed where the patient lacks capacity and resists examination or requires a specialist invasive investigation that would ordinarily involve written consent.

Also, nothing in the 2000 Act detracts from the duty to act in emergency situations. In Scotland, the common law doctrine of necessity permits urgent interventions to save life or prevent serious harm. Urgent treatment can be given under the doctrine of necessity where the patient does not consent. It is important to document why the treatment was given.

Except in emergencies, treatment should be covered by a certificate in terms of section 47 of the Act. The certificate is available from the Scottish Government website. It is acceptable for practitioners to type out their own certificates but they must follow the exact wording of the certificate on the website. In acute situations where the patient has a delirium, it is best practice to issue certificates for relatively short periods and reassess. For longer term treatment, especially if there are multiple pathologies, it is best to use a treatment plan similar to the example in the code of practice.

While the section 47 certificate must be completed, there are situations where additional actions are needed. Some treatments, e.g. sterilisation, abortion, medication to reduce sex drive and ECT require either court authorisation or an independent opinion. Also, there may be a welfare proxy (attorney or guardian with the authority to consent to treatment). If so, the proxy must be approached for consent wherever practicable. It is important to identify on admission whether or not there is a welfare proxy, but it is ultimately the responsibility of the proxy to make him/herself known and to provide evidence of the powers they have. Of course, the proxy can only consent where the patient lacks capacity.

Most importantly, the principles of the 2000 Act are paramount. The clinician should document, as far as is possible, the use of the principles in making treatment decisions.

The 2003 Act can also authorise treatment but only for mental disorder. It may authorise treatment for physical health problems, but only if they are a direct cause or consequence of mental disorder. Therefore, it can be used to treat a chest infection that is the cause of a delirium but not a fracture sustained by a person with dementia.

There are problem situations which might arise.

\section{A) The patient resists or refuses}

The problem here is that the law is unclear on the use of force. Part five of the 2000 Act deals with medical treatment but only authorises force (or detention, see below) 'where immediately necessary and only for as long as is necessary'. For use of force beyond immediate necessity, an intervention order or guardianship, perhaps with a compliance order, may be needed. It is a difficult area and the law needs to be clearer in order to guide clinicians and protect patients. The Commission's 'Right to Treat' guidance ${ }^{10}$ offers some help, including tackling the problem of how to get a reluctant patient to hospital.

Case example: Ms R had alcohol-related brain damage and cervical cancer." She refused further investigation after an abnormal cervical smear. Health and social care practitioners involved family and friends but still failed to persuade her to accept treatment. They considered the use of force but decided that the distress she would suffer would not justify forcible treatment. This was a carefully made decision that the Commission's investigation did not criticise.

When Ms $\mathrm{R}$ became terminally ill in a care home, she had a large, bloody vaginal discharge. She refused intervention and staff left her in pain, discomfort and indignity because they wrongly thought they had no authority to intervene against Ms R's wishes. Advance care planning and better understanding of the law would have helped. 


\section{B) The welfare proxy disagrees}

A welfare proxy (attorney or guardian), with the specific authority to do so may consent or refuse consent to medical treatment. If the proxy refuses, the practitioner should discuss the reasons and try to come to an agreement. If the practitioner still wants to proceed, he/ she must contact the Commission who will appoint an independent 'nominated medical practitioner' to provide an opinion under section 50 of the 2000 Act. That opinion can be challenged by application to the Court of Session.

Sometimes, the proxy wishes the patient to receive a treatment that the practitioner does not want to prescribe. Again, it is good to discuss the matter, but in this scenario there is no role for a nominated medical practitioner. Legally, a patient cannot insist that a treatment is given. The proxy can have no more power than the patient. The practitioner could offer a second opinion from a colleague to help resolve the dispute on an informal basis.

In all cases, it is very important to check that the proxy has the specific power to consent or refuse consent. General statements in the document conferring welfare powers are insufficient. We advise asking the proxy to produce the document and keeping a copy of it in the case record.

\section{C) Someone else objects}

Relatives or friends without any formal legal powers sometimes object to certain medical treatments. Everything stated above regarding discussion applies, but the only legal route open to them is an application to the Sheriff under section 52 of the 2000 Act for an injunction.

I have not covered end-of-life decisions, especially where treatment may be withheld or withdrawn. Clinicians should follow the GMC guidance on this. ${ }^{12}$

Treating a patient who is incapable of consenting requires care, good consultation and attention to the requirements of the 2000 Act. The most important points are:

- In emergency situations, document the reasons why urgent intervention was necessary.

- In other situations, record your assessment of capacity and complete a section 47 certificate (and treatment plan if necessary).

- Follow the principles of the 2000 Act and document how you have done this.

- Make sure there are good systems to record if there is a welfare proxy and maintain good communication with him/her.

- If force is required, follow the Commission's Right to Treat guidance.

\section{Deprivation of liberty}

A full analysis of the complex issue of deprivation of liberty would take an article much bigger than this to explore. Even then, it would leave the clinician with significant uncertainty. Practitioners will, for very good reasons, prevent confused patients from leaving hospital and restrict their movements to keep them safe. Mechanisms to achieve this include direct physical restraints (e.g. lap restraints, bed rails), chemical restraint with sedative medication, nursing interventions to observe and redirect the patient, locked doors and technology such as passive alarms and 'wandering technology'.

Again, the principles of the 2000 Act will help. Balancing benefit with least restrictive interventions and the views of the patient and others forms the key to good decisionmaking here. The Commission has guidance on restraint in general (Rights, Risks and Limits to Freedom) and wandering technology (Safe to Wander). These documents contain general guidance and specific recommendations for certain types of restraint. They are currently being updated (www.mwcscot.org.uk).

One particular issue needs to be addressed within this paper; the legality of restricting movement, especially to prevent a patient from leaving hospital. In this regard, the practitioner must be aware of the European Court judgement in the 'Bournewood' case. ${ }^{13}$

Case example: $\mathrm{HL}$ was a man with autistic spectrum disorder who was in hospital. His carers wanted to remove him from hospital; staff refused to let him leave but did not formally detain him. He appeared willing to stay in hospital between visits, but also appeared willing to leave with his carers. This case was appealed all the way to the European Court who decided that HL had been unlawfully deprived of his liberty.

This and other court judgements paint a complex picture of the legality of preventing patients who lack capacity from leaving hospital. Also, the legal situation of moving a patient from hospital to a care home causes significant problems. At the time of writing, the Scottish Law Commission is consulting over the recommendation to amend the present legislation in this area.

The Mental Welfare Commission does not take the view that all patients who lack capacity to decide to accept hospital admission should be formally detained, but we recognise the complexity of the issues. ${ }^{14}$ Some of the factors to consider are:

- The degree and intensity of control over the adult's movements.

- The length of time for which such controls might be needed.

- The intentions of those controlling the adult. 
- How the control is exercised: physical restraints can amount to detention, as can the use of sedation and observation.

- The extent of the adult's access to the outside world.

- Whether the cumulative effect of restrictions on the adult's life could amount to detention.

- Whether the adult is likely to indicate that he or she wishes to leave.

Definitive guidance cannot be given in this paper but a few case examples might help. These are semi-fictitious, i.e. they are built on real cases, some of which have been combined or amended to preserve anonymity.

Case example: $\operatorname{Mr} \mathrm{A}$ has dementia and is in hospital recovering from pneumonia. Previously, he was a fit man who enjoyed hill-walking. He has no idea where he is and explores his environment. He walks about the ward constantly and has to be redirected away from doors as he may go out and get lost. When redirected, he accepts this and does not appear to be making purposeful attempts to leave.

In the short term, this is not a deprivation of liberty. He needs to be kept safe to ensure his recovery from illness and he does not apparently have a desire to leave that is being thwarted. Observation and electronic tagging are acceptable without the need to formally authorise these by detaining him, although all decisions need to accord with the principles of the 2000 Act. If this situation continues, there may be a deprivation of liberty if he is not able to enjoy his previous walking activity. Access to open space, including safe accompanied walks, would be necessary to avoid accusations of deprivation of liberty.

The above example illustrates that it is the purpose of the restraint (in its broadest sense), not the restraint itself that determines whether or not there is a deprivation of liberty. For Mr A, it would not matter whether or not the door was locked, but a blanket measure such as this might unlawfully deprive others of liberty. The Commission advises against blanket measures, where possible.

Case example: Ms B has alcohol-related brain damage. She was admitted acutely confused and ataxic.After a few weeks, she is very much better and wants to go home. She is persuaded to stay on the basis that she is being assessed for safety at home, although needs frequent reminders about this. Home assessment shows that she is clearly unsafe and the plan is for residential care. Ms B continues to want to go home and staff continue to dissuade her by telling her she is still being assessed.

This is more complex. During the period of assessment, it may be reasonable to tell her that it is unsafe for her to go home until assessments have been completed. Formal detention may not be necessary depending on the frequency and vehemence of her wishes to leave (she does not retain the information about ongoing assessment). However, when staff continue to tell her she is still being assessed when the plan is clearly that she does not go home, this is likely to constitute a deprivation of liberty and formal measures should be put in place to authorise this.

Note in this example that legality and kindness are separate. It may not be legal to keep Ms B in hospital informally when the clear ongoing intention is to thwart her wish to go home. But it may be unkind to confront her with this, especially as it may be necessary to do this repeatedly and distress her.

In the short-term, mental health legislation might be needed while the situation is assessed. In the longer term, welfare guardianship might be necessary. The local authority has the duty to apply for guardianship if no other application is likely to be made.

This is a difficult area for general hospitals. Where there is doubt or dispute, anyone with an interest in the patient's welfare can apply to the Mental Health Tribunal for an order that the patient is being unlawfully de facto detained. The best advice, by way of summary, is:

- You have a duty of care. The patient's safety should be your first concern.

- If the cumulative effect of measures to ensure safety deprives the patient of liberty, especially by thwarting a desire to leave, then you should consider formal measures to detain him/her.

- Do not confuse legality with kindness. It may be necessary to divert or distract the patient by being untruthful, but where this deprives the patient of liberty, legal measures should be in place.

- The Mental Health Tribunal has the authority to rule that there is unlawful de facto detention.

\section{OTHER UK JURISDICTIONS}

The law on incapacity differs across the UK. In England and Wales, the Mental Capacity Act (2005) (MCA) applies. This includes additional Deprivation of Liberty (DoL) safeguards introduced into the legislation in 2007. There are many important differences between these and the law in Scotland. Most importantly, the MCA has a general authority to intervene that has no equivalent in Scottish Law. The DoL safeguards are cumbersome, involve several reports to an authorising body and have been implemented inconsistently across England and Wales.

Northern Ireland has no equivalent incapacity legislation, 
although there are proposals to introduce a single Bill covering mental health and incapacity law. At present, practitioners in Northern Ireland rely on common law duty of care. This gives inadequate protection to patients and practitioners. For a further analysis, see Different Laws, Same Principles: Mental Health and Incapacity Legislation Across the UK. ${ }^{15}$

\section{REFERENCES}

I Ward A. Adult incapacity. Edinburgh:W Green \& Son; 2003.

2 Patrick H. Mental health, incapacity and the law in Scotland. Edinburgh: Tottel; 2006.

3 Mental Welfare Commission for Scotland. Dementia: decisions for dignity [Internet]. Edinburgh: MWCS; 20II [cited 2013 Jan 18]. Available from: http://www.mwcscot.org.uk/media/53/87/ Decisions\%20for\%20Dignity\%202010.pdf

4 Healthcare Improvement Scotland. Care for older people in acute hospitals: six-monthly report (February to July 20/2) [Internet] Edinburgh: HIS; 2012 [cited 2013 Jan I8].Available from: http://www. healthcareimprovementscotland.org/our_work/inspecting_and regulating_care/opah_six-monthly_reports/opah_six-monthly_ rep_oct_20I2.aspx

5 Mental Welfare Commission for Scotland. Investigation into the care and treatment of Mrs T [Internet]. Edinburgh MWCS; 2007 [cited 2013 Jan 18]. Available from: http://www.mwcscot.org.uk/ media/52007/Mrs\%20T\%20enquiry.pdf

$6 \operatorname{Re} C$ (Adult, refusal of treatment) [1994] I All ER 8 I9.

7 General Medical Council. Consent guidance: patients and doctors making decisions together [Internet]. London: GMC; 2008 [cited 2013 Jan 18]. Available from: http://www.gmc-uk.org/guidance/ethical_ guidance/consent_guidance_index.asp

8 Mental Welfare Commission for Scotland. Consent to treatment [Internet]. Edinburgh: MWCS; 2010 [cited 2013 Jan I8]. Available from: http://www.mwcscot.org.uk/media/5I774/Consent\%20 to\%20Treatment.pdf

\section{CONCLUSION}

Good legal and ethical management of the confused patient requires some knowledge of articles of human rights law and principles of incapacity law in Scotland. Proper assessment of capacity, good consultation with relatives and proxies and reference to the guidance documents are outlined in this paper.

9 Mental Welfare Commission for Scotland. Powers of attorney and their safeguards [Internet]. Edinburgh: MWCS; 2012 [cited 2013 Jan 18]. Available from: http://www.mwcscot.org.uk/media/56/40/ powers_of_attorney_and_their_safeguards.pdt

10 Mental Welfare Commission for Scotland. Right to treat [Internet] Edinburgh: MWCS; 201 I [cited 2013 Jan I8].Available from: http:// www.mwcscot.org.uk/media/5 I822/Right\%20to\%20Treat.pdf

II Mental Welfare Commission for Scotland. Ms $R$ report. Edinburgh: MWCS; 2012 [cited 2013 Jan 18]. Available from: http://www. mwcscot.org.uk/media/89873/mwc_msr_report_web.pdf

12 General Medical Council. Treatment and care towards the end of life: good practice in decision-making [Internet]. London: GMC; 2010 [cited 2013 Jan 18]. Available from: http://www.gmc-uk.org/guidance/ ethical_guidance/end_of_life_care.asp

I3 European Court of Human Rights HL v UK ECHR 47I. 2004.

14 Patrick H. Autonomy, benefit and protection [Internet]. Edinburgh: MWCS; 2008 [cited 2013 Jan 18]. Available from: http://www. mwcscot.org.uk/media/5 I750/Autonomy,_benefit_and protection.pdf

I5 Lyons D. Different laws, same principles: mental health and incapacity legislation across the UK. Advances in psychiatric treatment 2010; 16: I 58-60. http://dx.doi.org/I0.I | 92/apt.bp. I09.00783 | 